\title{
The Control of the Morphology of MnS Inclusions in Steel during Solidification
}

\author{
Katsunari OIKAWA, Hiroshi OHTANI, ${ }^{1)}$ Kiyohito ISHIDA") and Taiji NISHIZAWA2)
}

Graduate School, Tohoku University, Aramaki, Aoba-ku, Sendai, Miyagi-ken, 980-77 Japan.

1) Department of Materials Science, Faculty of Engineering, Tohoku University, Aramaki, Aoba-ku, Sendai, Miyagi-ken, 980-77 Japan. $\quad 2$ 2) Formerly Department of Materials Science, Faculty of Engineering, Tohoku University. Now at Sumitomo Metal Industries, Ltd., Research \& Development Center, Fuso-cho, Amagasaki, Hyogo-ken, 660 Japan.

(Received on November 15, 1994; accepted in final form on December 16, 1994)

\begin{abstract}
The morphology of $\mathrm{MnS}$ inclusions in steel formed during solidification and the modification of this morphology by additions of alloying elements $\mathrm{Al}, \mathrm{Si}, \mathrm{C}$ and $\mathrm{Ti}$ have been investigated using optical and electron microscopy techniques.

In sulfur-lean melts the morphology of the secondary MnS inclusion formed after the primary crystallization of the Fe phase during solidification can be classified under the following categories: i) Globular or droplet shaped MnS resulting from a monotectic reaction, ii) Rod like MnS formed through an eutectic reaction and $\mathrm{iii)} \mathrm{a} \mathrm{fish-bone} \mathrm{type} \mathrm{MnS}$ formed as a result of an irregular eutectic reaction. In sulfur-rich melts the primary crystallization phase is $\mathrm{MnS}$ and depending on the nature of additional elements present in the melt and the melt atmosphere, the morphology of these primary MnS inclusions can be classified as iv) spherical, v) dendritic or vi) angular.

The formation mechanism of the different MnS morphologies is discussed on the basis of phase diagram information. It is shown that the spherical morphology of the primary and secondary MnS inclusions is a result of metastable reactions, while the eutectic, dendritic and angular morphologies are the products of stable reactions, with the high melting dispersed particles like $\mathrm{TiN}$ and $\mathrm{Al}_{2} \mathrm{O}_{3}$ acting as nucleants for the $\mathrm{MnS}$ crystals. It is also shown that the addition of $\mathrm{C}$ and $\mathrm{Si}$ increases the probability of stable reactions by increasing the temperature interval between the eutectic and the monotectic points.
\end{abstract}

KEY WORDS: manganese sulfide; inclusion; morphology; solidification; phase diagram; metastable reaction.

\section{Introduction}

Because non-metallic inclusions in steels are generally detrimental to their material properties, considerable efforts have been directed towards the development of alloys and processes to reduce their presence in steels to a minimum. However, of late, the utilization of inclusions for the control of microstructures is becoming a subject of considerable interest for improving the mechanical properties of steels. ${ }^{1)}$

The beneficial effects of manganese sulfide inclusions in improving machinability and retarding grain growth in steels are well known. Since the morphology of these sulfide inclusions has a significant effect on the various properties of steels, numerous studies focusing on establishing the relation between solidification conditions and the morphology of the $\mathrm{MnS}$ inclusions have been conducted over the years. ${ }^{2-8)}$ According to the classical work by Sims and Dahle, ${ }^{2)}$ the morphology of MnS can be broadly classified into three types: i.e., (1) randomly dispersed globular sulfides (Type I), (2) rod-like fine sulfides (Type II), and (3) angular sulfides (Type III). In addition to these types, dendritic sulfides have also been detected and the effect of alloying elements, such as $\mathrm{Al}$,
$\mathrm{C}$, and $\mathrm{Si}$ on the morphology of $\mathrm{MnS}$ has also been reported. ${ }^{2-8)}$ However the mechanism of the evolution of the different morphologies and their modification by various additions is still uncertain.

In view of these facts, the present study has been undertaken with a view to identifying and elucidating the role of the principal factors that control the morphological evolution of $\mathrm{MnS}$ in cast steels, using both experimental techniques and theoretical thermodynamic analysis.

\section{Experimental Procedure}

Firstly, $40 \mathrm{~mm}$ diameter and $30 \mathrm{~mm}$ long cylindrical alloy castings weighing $300 \mathrm{~g}$ were prepared by taking electrolytic iron, electrolytic manganese and iron sulfide, each of $99.9 \%$ purity, and high purity ferroalloys of $\mathrm{Si}$, $\mathrm{Al}, \mathrm{Ti}$ or $\mathrm{C}$ as and when required, and melting them in magnesia crucibles in an induction furnace, under an Ar atmosphere. Only in case of alloys where the role of TiN was to be studied, the melting atmosphere in the induction furnace was chosen to be $\mathrm{N}_{2}$. After melting, the alloys were kept at around $1600^{\circ} \mathrm{C}$ in the molten state for several minutes, and then allowed to solidify in 
the crucibles themselves. The measured cooling rate in the solidification range was about $30^{\circ} \mathrm{C} / \mathrm{min}$.

Two series of alloys were prepared: (1) A sulfur-lean, $\mathrm{Fe}-1 \mathrm{mass} \% \mathrm{Mn}-0.3$ mass $\% \mathrm{~S}$ series in which $\mathrm{MnS}$ was formed as the secondary phase during solidification, and (2) a sulfur-rich, Fe-2.5mass $\% \mathrm{Mn}-(1.0-1.7) \mathrm{mass} \% \mathrm{~S}$ series in which $\mathrm{MnS}$ was formed as the primary phase during solidification. Typical examples of oxygen and nitrogen contents in selected alloy specimens are shown in Table 1.

Microstructural examination of the specimens was carried out using an optical microscope (OM) and a scanning electron microscope (SEM). Specimens for microstructural examination were taken from a region $10 \mathrm{~mm}$ away from the bottom of the ingots. The sections to be examined by SEM were mechanically polished and then etched electrolytically in $1 \%$ tetramethylammonium chloride-10\%acetylacetone-methanol.

\section{Experimental Results}

\subsection{Morphology of the Secondary MnS Phase}

The morphology of the secondary $\mathrm{MnS}$ phase that evolves during the solidification of the alloys of the $\mathrm{Fe}-1 \mathrm{Mn}-0.3 \mathrm{~S}$ series is classified under three types as follows.

\subsubsection{Monotectic MnS}

Typical micrographs of this type of $\mathrm{MnS}$ are shown in Fig. 1. These sulfide phases have a droplet shape of

Table 1. Content of oxygen and nitrogen in typical specimens. (mass\%)

\begin{tabular}{cccccc}
\hline $\mathrm{Mn}$ & $\mathrm{S}$ & $X$ & $\mathrm{O}$ & $\mathrm{N}$ & Atmosphere \\
\hline$(2.5)$ & $(1.3)$ & - & 0.0135 & 0.0005 & $\mathrm{Ar}$ \\
$(1.0)$ & $(0.3)$ & $\mathrm{Si}(1.0)$ & 0.0048 & 0.0004 & $\mathrm{Ar}$ \\
$(1.0)$ & $(0.3)$ & $\mathrm{Al}(0.1)$ & 0.0017 & 0.0011 & $\mathrm{Ar}$ \\
$(1.0)$ & $(0.3)$ & $\mathrm{Al}(0.2)$ & 0.0004 & 0.0008 & $\mathrm{Ar}$ \\
$(2.5)$ & $(1.0)$ & $\mathrm{Ti}(0.1)$ & 0.0014 & 0.0396 & $\mathrm{~N}_{2}$ \\
\hline
\end{tabular}

( ) charged value
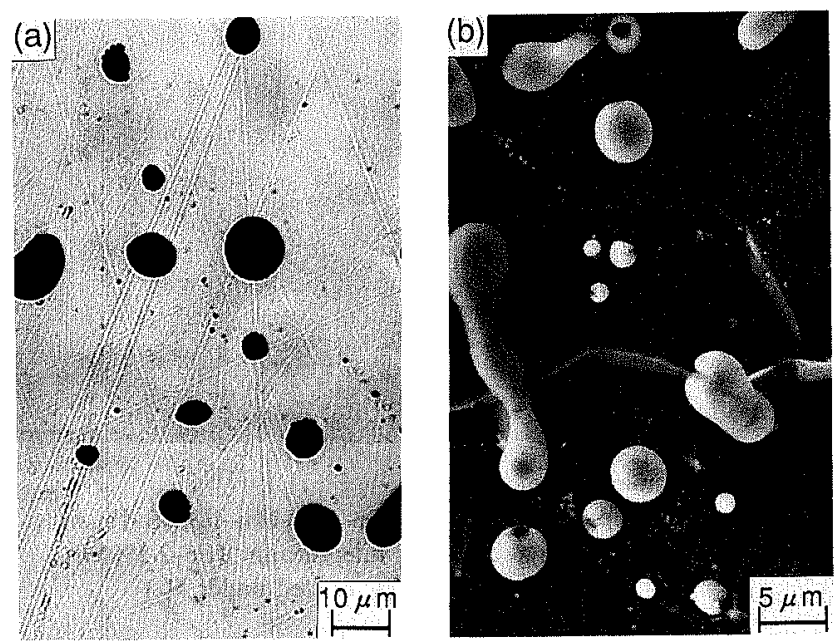

Fig. 1. Monotectic MnS.

(a) optical micrograph $(\mathrm{Fe}-1 \% \mathrm{Mn}-0.3 \% \mathrm{~S}-0.1 \% \mathrm{Ti})$

(b) scanning electron micrograph (Fe-1\% $\mathrm{Mn}-$ $0.3 \% \mathrm{~S})$ about $10 \mu \mathrm{m}$ in diameter, which seems to correspond to the Type I globular morphology in Sims' classification. ${ }^{2)}$ As will be discussed in a later section, since these sulfide phases are expected to be formed through the metastable monotectic reaction $\left(\mathrm{L}_{1} \rightarrow \mathrm{Fe}(\mathrm{s})+\mathrm{L}_{2}\right)$, they shall be termed the monotectic $\mathrm{MnS}$ hereafter.

\subsubsection{Eutectic MnS}

Typical micrographs of $\mathrm{MnS}$ of the eutectic morphology which seem to correspond to the Type II morphology in Sims' classification, ${ }^{2)}$ are shown in Fig. 2. This type is characterized by an assembly of fine rod-like sulfides and has been variously considered to be the result of either the eutectic reaction $\left(\mathrm{L}_{1} \rightarrow \mathrm{Fe}(\mathrm{s})+\mathrm{MnS}\right)^{3)}$ or the monotectic reaction $\left(\mathrm{L}_{1} \rightarrow \mathrm{Fe}(\mathrm{s})+\mathrm{L}_{2}\right){ }^{5-7)}$ Fredriksson and Hillert ${ }^{5,6)}$ were of the opinion that these sulfides formed through the cooperative monotectic reaction, citing as evidence the fact that most of the tips of rod-like $\mathrm{MnS}$ are rounded as seen in Fig. 2(b). However, there exists a possibility that the rounded tips can also be the result of a possible local rise in temperature due to
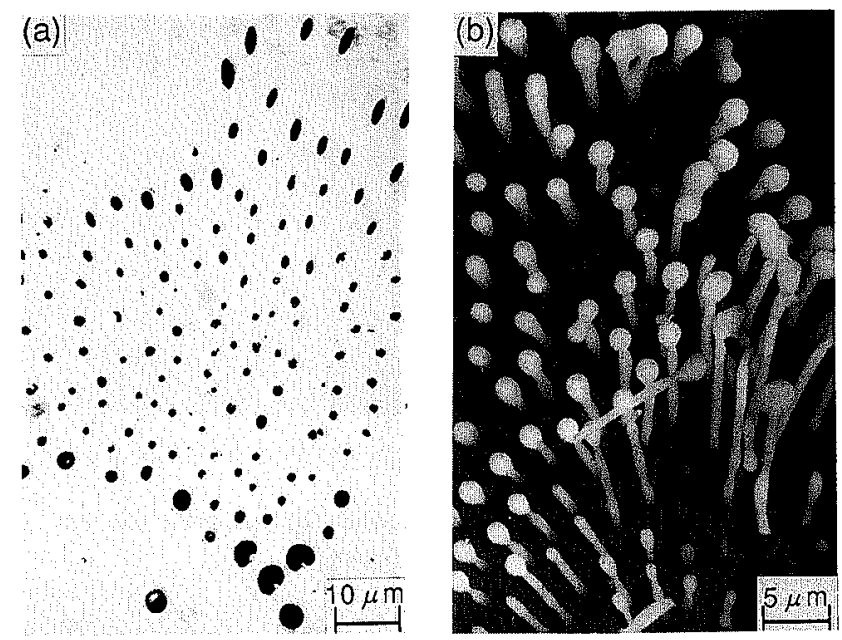

Fig. 2. Rod-like eutectic $\mathrm{MnS}$ in $\mathrm{Fe}-1 \% \mathrm{Mn}-0.3 \% \mathrm{~S}-0.1 \% \mathrm{Ti}$, melted under $\mathrm{N}_{2}$

(a) optical micrograph and (b) scanning electron micrograph
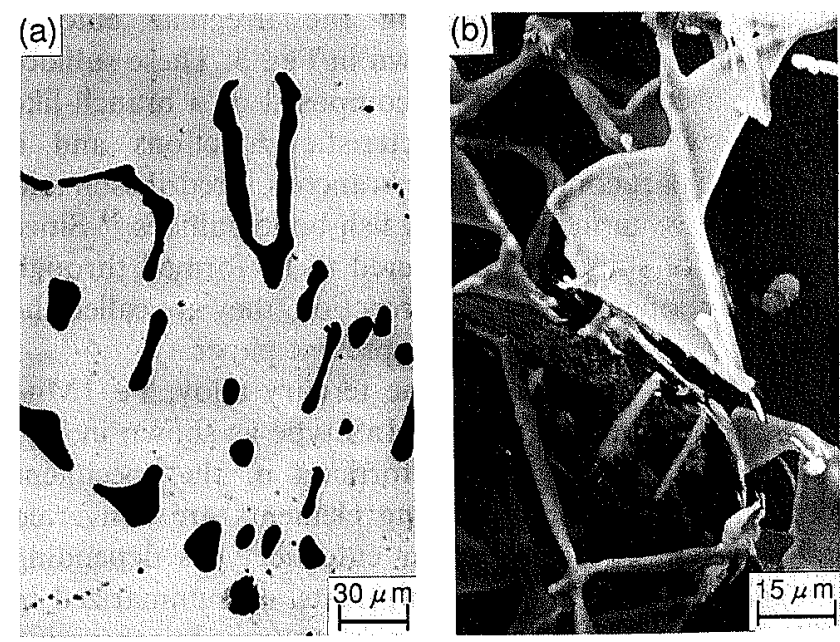

Fig. 3. Irregular eutectic $\mathrm{MnS}$.

(a) optical micrograph $(\mathrm{Fe}-1 \% \mathrm{Mn}-0.3 \% \mathrm{~S}-1 \% \mathrm{C}$ )

(b) scanning electron micrograph (Fe-1\%Mn$0.3 \% \mathrm{~S}-5 \% \mathrm{Si}$ 


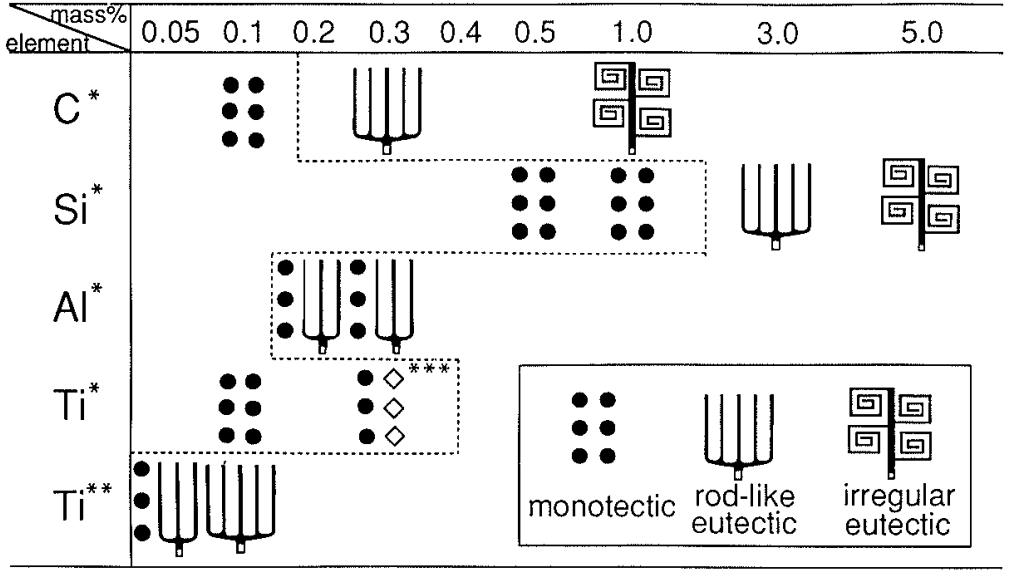

Fig. 4.

Morphology of $\mathrm{MnS}$ in hypo-eutectic (or -monotectic) specimens containing $\mathrm{C}, \mathrm{Si}, \mathrm{Al}$ and $\mathrm{Ti}$.
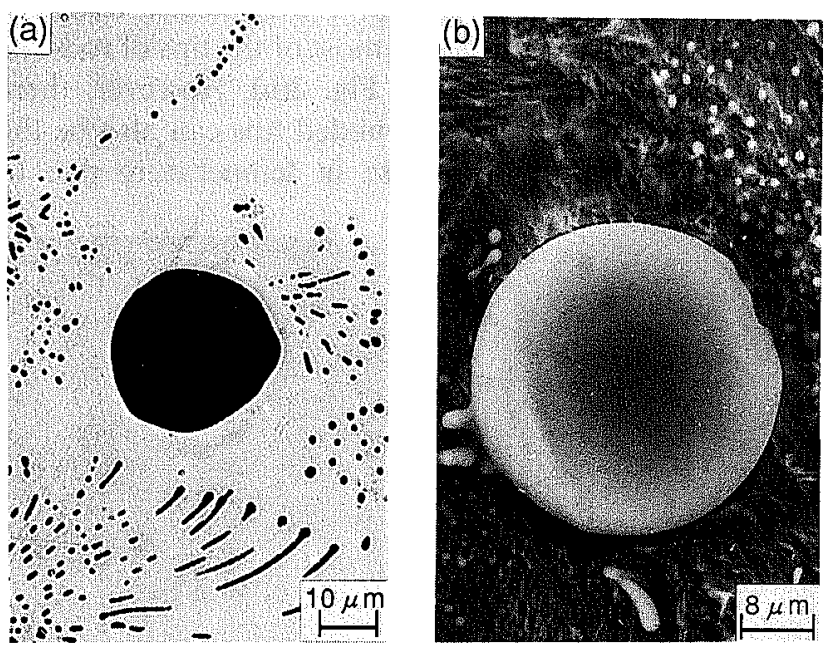

Fig. 5. Primary spherical $\mathrm{MnS}$ in $\mathrm{Fe}-2.5 \% \mathrm{Mn}-1.3 \% \mathrm{~S}-$ $0.3 \% \mathrm{C}$.

(a) optical micrograph and (b) scanning electron micrograph

recalescence in the last stages of the eutectic reaction. Since it is felt that there exists a sound thermodynamic basis for this assertion, as will be explained later, the fine rod-like sulfides are classified as the eutectic $\mathrm{MnS}$.

\subsubsection{Irregular Eutectic $\mathrm{MnS}$}

The micrographs showing the irregular eutectic morphology of MnS are shown in Fig. 3. These sulfides exhibit a complex structure composed of a branch-like part growing along characteristic directions and a plate-like part connecting the branches. Fredriksson and Hillert have termed these as fish-bone sulfides. ${ }^{5)}$ Since this type of sulfide is considered to be formed through the non-cooperative eutectic reaction, they are called the irregular eutectic $\mathrm{MnS}$ in the present paper.

The sulfides forming in the ternary alloy, Fe-1Mn$0.3 \mathrm{~S}$, are of the monotectic $\mathrm{MnS}$ type as shown in Fig. 1(b), whereas the sulfides forming in the specimens containing additional alloying elements are converted into the eutectic or irregular eutectic types depending on the content of alloying elements, as summarized in Fig. 4. The sulfides forming in the specimens containing the additional alloying element $\mathrm{C}$ or $\mathrm{Si}$ change from the monotectic to the irregular eutectic $\mathrm{MnS}$ through the eutectic one, as the alloying content is increased,
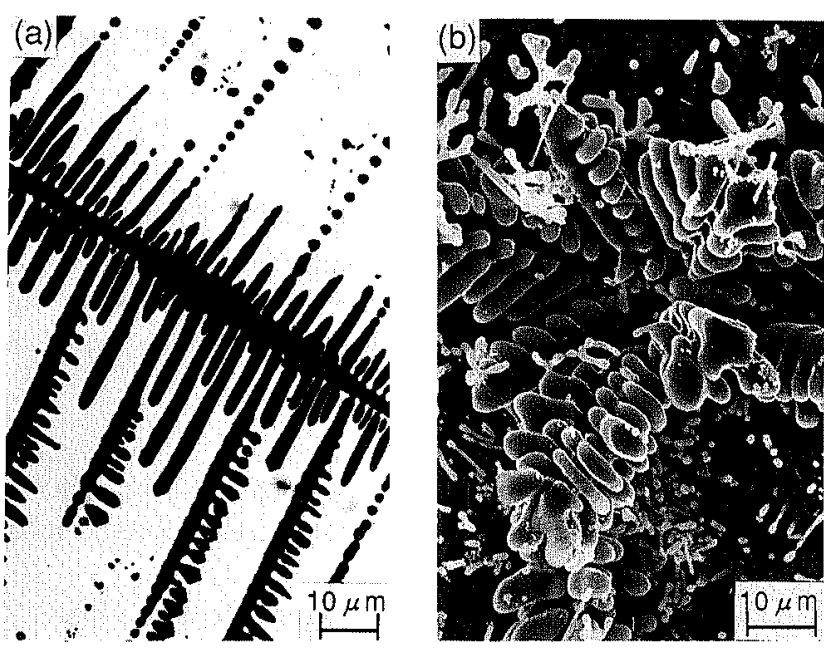

Fig. 6. Primary dendritic $\mathrm{MnS}$.

(a) optical micrograph (Fe-4\% Mn-2\%S-0.5\% Al$0.3 \% \mathrm{C}$ )

(b) scanning electron micrograph (Fe-2.5\% Mn$1.3 \% \mathrm{~S}-0.5 \% \mathrm{Al})$
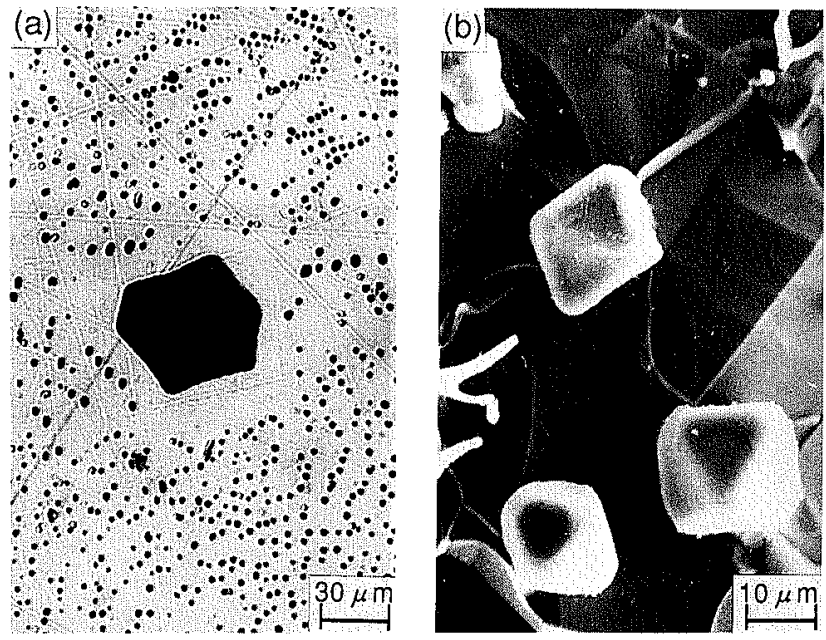

Fig. 7. Primary angular $\mathrm{MnS}$.

(a) optical micrograph $(\mathrm{Fe}-2.5 \% \mathrm{Mn}-1.3 \% \mathrm{~S}-1 \% \mathrm{Al})$

(b) scanning electron micrograph (Fe-2.5\% Mn$1.3 \% \mathrm{~S}-0.5 \% \mathrm{Al}-0.1 \mathrm{Ti}$, melted under $\mathrm{N}_{2}$ )

whereas the addition of $\mathrm{Al}$ or $\mathrm{Ti}$ (under $\mathrm{N}_{2}$ ) causes a morphological change from the monotectic to the eutectic. The specimens alloyed with Ti (under Ar) exhibit 


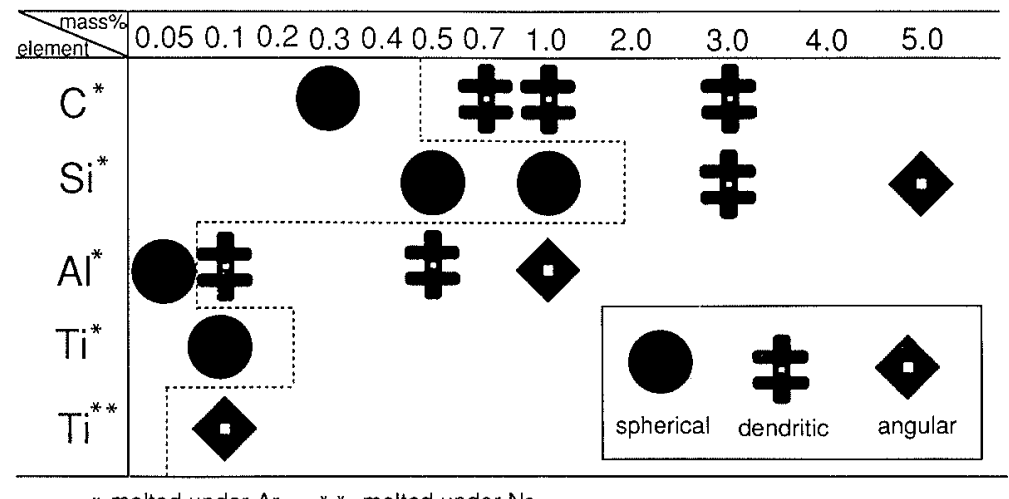

Fig. 8.

Morphology of primary $\mathrm{MnS}$ in hyper-eutectic (or -monotectic) specimens containing $\mathrm{C}, \mathrm{Si}, \mathrm{Al}$ and $\mathrm{Ti}$. only the monotectic $\mathrm{MnS}$, though the eutectic TiS coexists with $\mathrm{MnS}$ in the specimens containing more than $0.3 \% \mathrm{Ti}$

\subsection{Morphology of the Primary MnS Phase}

In the alloy specimens of the sulfur-rich Fe-2.5Mn(1.5-1.7)S series, the sulfides are formed as the primary phase occurring in three morphological types as follows.

\subsubsection{Spherical MnS}

Typical micrographs of the spherical MnS are shown in Fig. 5. Since this type of sulfides has a spherical shape with a diameter of $30-50 \mu \mathrm{m}$, it is obvious that both the matrix Fe phase and the dispersed $\mathrm{MnS}$ phase are in the molten state at the instant of separation, and the spherical $\mathrm{MnS}$ is formed through the two-phase separation of liquid.

\subsubsection{Dendritic $\mathrm{MnS}$}

The micrographs of the dendritic $\mathrm{MnS}$ are shown in Fig. 6. This type of sulfides seems to be formed by primary crystallization in a highly supersaturated liquid.

\subsubsection{Angular $\mathrm{MnS}$}

This type of MnS shows an octahedral or tetrakaidecahedral shape as shown in Fig. 7. This seems to correspond to the Type III morphology in Sims' classification, ${ }^{2)}$ formed by primary crystallization under a small degree of supersaturation.

The spherical $\mathrm{MnS}$ is the only primary sulfide observed in the ternary alloy ( $\mathrm{Fe}-2.5 \mathrm{Mn}-1.3 \mathrm{~S})$. The others are observed in the specimens containing alloying elements as summarized in Fig. 8. Progressive additions of Si, Al and $\mathrm{Ti}$ (under $\mathrm{N}_{2}$ ), alter the morphology of the primary $\mathrm{MnS}$ from the spherical to angular type through the dendritic type. Additions of carbon also result in a change from the spherical to the dendritic types, but no angular type $\mathrm{MnS}$ is formed. There is no morphological change with the addition of $\mathrm{Ti}$ (under Ar).

\section{Discussion}

\subsection{Stable and Metastable Fe-Mn-S Systems}

According to the equilibrium phase diagram of the $\mathrm{Fe}-\mathrm{Mn}-\mathrm{S}$ system, ${ }^{10-12)}$ any Fe-rich melt $\left(\mathrm{L}_{1}\right)$, on cooling from the liquid state, would be expected to follow a solidification path that would result in the solidification of the primary $\mathrm{Fe}$ phase first, followed by a eutectic solidification according to the eutectic reaction $\left(\mathrm{L}_{1} \rightarrow\right.$
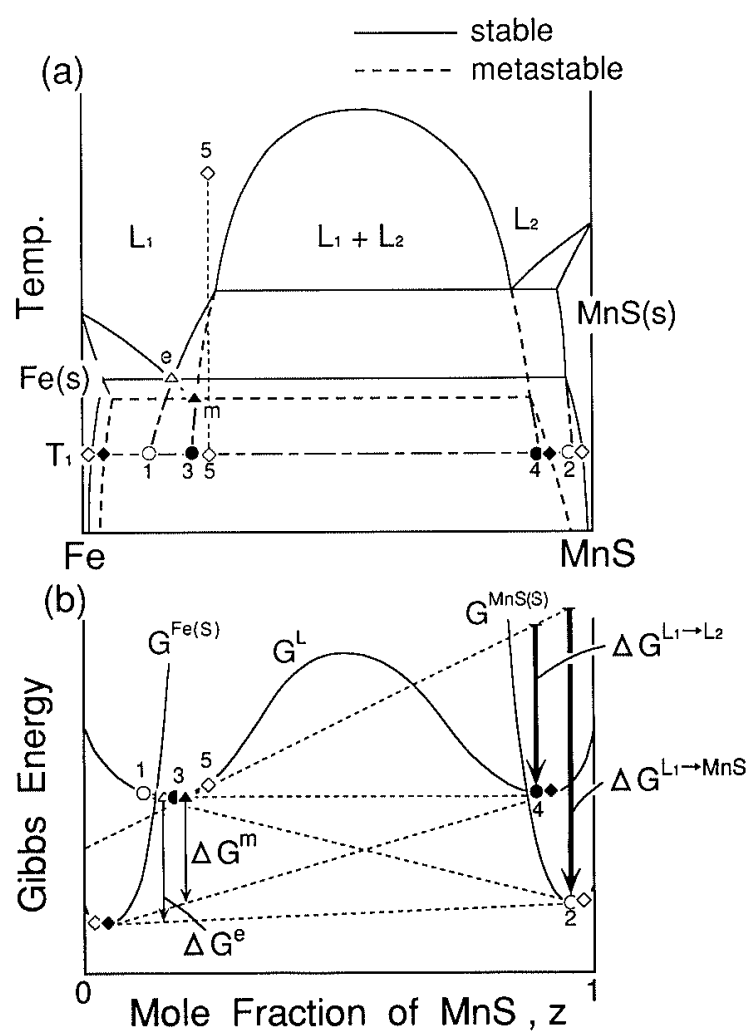

Fig. 9. Schematic diagrams for the Fe-MnS pseudo-binary in stable and metastable systems.

(a) phase diagram and (b) free energy diagram at $T_{1}$

$\mathrm{Fe}(\mathrm{s})+\mathrm{MnS}(\mathrm{s}))$. This would preclude the formation of any globular or droplet type $\mathrm{MnS}$ because the droplet type MnS would result only when the solidification path involves the monotectic reaction $\left(\mathrm{L}_{1} \rightarrow \mathrm{Fe}(\mathrm{s})+\mathrm{L}_{2}\right)$. However the globular or the droplet type $\mathrm{MnS}$ has always been observed in $\mathrm{Fe}-\mathrm{Mn}-\mathrm{S}$ ternary alloys cooled from the liquid state in a normal way. Some previous studies $^{2-8)}$ have been tried to explain the formation of this type of sulfide as arising from the lowering of the melting temperature of $\mathrm{MnS}$ to below the eutectic temperature because of oxygen contamination. This explanation is not valid because, according to the MnS-MnO phase diagram, ${ }^{9)}$ such a possibility would arise only when the oxygen content of the $\mathrm{L}_{2}$ liquid exceeds $25 \%$. Furthermore the monotectic $\mathrm{MnS}$ has been observed even in the presence of strong deoxidisers like $\mathrm{Ti}, \mathrm{C}$ and $\mathrm{Si}$ as shown in Fig. 4.

In order to explain the occurrence of the globular type 
$\mathrm{MnS}$ in $\mathrm{Fe}-\mathrm{Mn}-\mathrm{S}$ alloys the existence of a metastable phase diagram is invoked here. The schematic outline of the stable and metastable phase equilibria in the $\mathrm{Fe}-\mathrm{MnS}$ pseudo-binary system is drawn in Fig. 9, where the solid and broken lines represent the stable and metastable equilibria respectively. The actual calculated stable and metastable phase equilibria in the Fe-rich portion are also shown in Fig. 10. The calculated difference between the eutectic point $(e)$ and the monotectic point $(m)$ is so small (only $3^{\circ} \mathrm{C}$ ) that a metastable monotectic reaction leading to the formation of the globular MnS becomes a distinct possibility.

The method by which the metastable diagram in Fig. 10 is obtained, is described below. The solubility product of $\mathrm{MnS}(\mathrm{s})$ in liquid $\mathrm{Fe}$ is estimated from the experimental data $^{11)}$ as follows.

$$
\log [\% \mathrm{Mn}] \cdot[\% \mathrm{~S}]=-\frac{9200}{T}+5.3
$$

The solubility curve for $\mathrm{MnS}(\mathrm{s})(z$; line a, b in Fig. 10 ) in the $\mathrm{Fe}-\mathrm{MnS}$ pseudo-binary system can be derived from Eq. (1) as the next equation.

$$
z \approx \exp \left[\frac{-88080+25.0 T}{R T}\right]
$$

The Gibbs energy difference between $\mathrm{MnS}(\mathrm{s})$ and $\operatorname{MnS}\left(\mathrm{L}_{2}\right)$ has been given by Hillert and Staffansson ${ }^{12)}$ as follows.

$$
\Delta G_{\mathrm{MnS}}^{\mathrm{s} \rightarrow \mathrm{L}_{2}}=13054-6.625 T \mathrm{~J} / \mathrm{g} \cdot \text { atom }
$$

Since the numerator value in the square bracket of Eq. (2) corresponds to the Gibbs energy of formation of $\mathrm{MnS}(\mathrm{s})$, the solubility curve for $\operatorname{MnS}\left(\mathrm{L}_{2}\right)\left(z^{\prime}\right.$; line $\mathrm{c}, \mathrm{d}$ in Fig. 10) is derived from Eqs. (2) and (3) as follows.

$$
z^{\prime} \approx \exp \left[\frac{-75030+18.4 T}{R T}\right]
$$

The liquidus line in Fig. 10 (line $\mathrm{f}, \mathrm{g}$ ) is estimated from

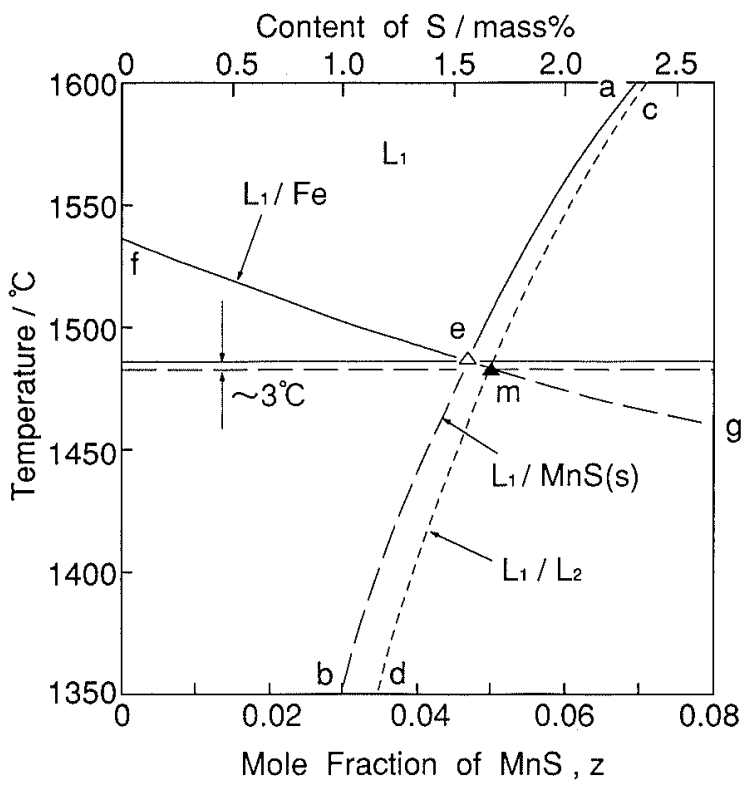

Fig. 10. Phase equilibria in the Fe-rich region of Fe-MnS pseudo-binary system, estimated from the data on solubility of $\mathrm{MnS}$ in molten iron. the $\mathrm{Fe}-\mathrm{S}$ binary system. ${ }^{13)}$

\subsection{Driving Force for the Nucleation of $\mathrm{MnS}$}

$\Delta G^{m}$ and $\Delta G^{e}$ shown by thin arrows in Fig. 9(b) denote the steady state driving forces for the metastable monotectic and stable eutectic reactions respectively. In order to determine which of these reactions would be preferred during solidification, it would be necessary to examine the free energy differences $\Delta G^{\mathrm{L}_{1} \rightarrow \mathrm{L}_{2}}$ and $\Delta G^{\mathrm{L}_{1} \rightarrow \mathrm{MnS}}$ denoted by the thick lines in Fig. 9(b), which would induce the nucleation of $\mathrm{L}_{2}$ or $\mathrm{MnS}$ (s) from $\mathrm{L}_{1}$.

Assuming that a spherical nucleus is formed in the supercooled $\mathrm{L}_{1}$ phase at $T_{1}$, the Gibbs energy change due to the formation of the nucleus can be expressed by the next equation.

$$
\Delta g=\frac{4}{3} \pi r^{3} \frac{\Delta G}{V}+4 \pi r^{2} \sigma
$$

where, $\Delta G$ is $\Delta G^{\mathrm{L}_{1} \rightarrow \mathrm{L}_{2}}$ or $\Delta G^{\mathrm{L}_{1} \rightarrow \mathrm{MnS}}, V$ is the molar volume and $\sigma$ is the interfacial energy between $\mathrm{L}_{1}$ and $\operatorname{MnS}\left(\mathrm{L}_{2}\right)$ or $\mathrm{L}_{1}$ and $\mathrm{MnS}(\mathrm{s})$.

The maximum Gibbs energy change $\Delta g_{\max }$ and the critical radius $r_{c}$ are given by

$$
\begin{aligned}
& r_{c}=-\frac{2 \sigma V}{\Delta G} \\
& \Delta g_{\max }=\frac{16}{3} \pi V^{2} \frac{\sigma^{3}}{\Delta G^{2}}=\frac{4}{3} \pi r_{c}^{2} \sigma
\end{aligned}
$$

The driving force for the nucleation from a supersaturated liquid is generally approximated by $\Delta G \approx$ $-R T(\Delta z / z)$, where $z$ is the equilibrium solubility of $\mathrm{MnS}$ phase and $\Delta z$ the degree of supersaturation. $\Delta z$ itself is related to the undercooling $\Delta T$ by the expression $\Delta z / z \approx(Q / R T) \cdot \Delta T / T$ where $z=A \exp (-Q / R T)$. From these expressions it follows then that the driving force for nucleation at an undercooling level $\Delta T$ can be approximated by the next equation.

$$
\Delta G \approx-Q \cdot \frac{\Delta T}{T}
$$

From Eqs. (2) and (4) it is seen that the calculated values of $Q$ for $\mathrm{MnS}(\mathrm{s})$ and $\mathrm{MnS}\left(\mathrm{L}_{2}\right)$ are not likely to be very different. For example, $Q$ is equal to $43.8 \mathrm{~kJ} / \mathrm{mol}$ for $\mathrm{MnS}(\mathrm{s})$ and $42.4 \mathrm{~kJ} / \mathrm{mol}$ for $\mathrm{MnS}\left(\mathrm{L}_{2}\right)$ at $1500^{\circ} \mathrm{C}$. From Eq. (8) it is obvious that when the degree of supercooling is the same, the difference between $\Delta G^{\mathrm{L}_{1} \rightarrow \mathrm{L}_{2}}$ and $\Delta G^{\mathrm{L}_{1} \rightarrow \mathrm{MnS}}$ is going to be quite small. This fact suggests that the interfacial energy $\sigma$ in Eqs. (6) and (7) could play an important role in controlling the critical radius $r_{c}$ and thereby the energy barrier $\Delta g_{\max }$ for the nucleation.

\subsection{Interfacial Energy between Liquid Iron and MnS}

The values of the interfacial energies between liquid iron and liquid $\mathrm{MnS}\left(\mathrm{L}_{2}\right)$ or liquid and solid $\mathrm{MnS}(\mathrm{s})$ have not been determined experimentally. One can however, estimate the interfacial energy between $\mathrm{Fe}\left(\mathrm{L}_{1}\right)$ and $\mathrm{MnS}\left(\mathrm{L}_{2}\right)$ to be in the region of $0.2 \mathrm{~N} / \mathrm{m}$ by extrapolation of the data ${ }^{14)}$ on the interfacial energy of $\mathrm{Fe}\left(\mathrm{L}_{1}\right)$ and slag $\left(\mathrm{MnO}-\mathrm{SiO}_{2}-\mathrm{CaO}-\mathrm{MnS}\right.$ system) as shown in Fig. 


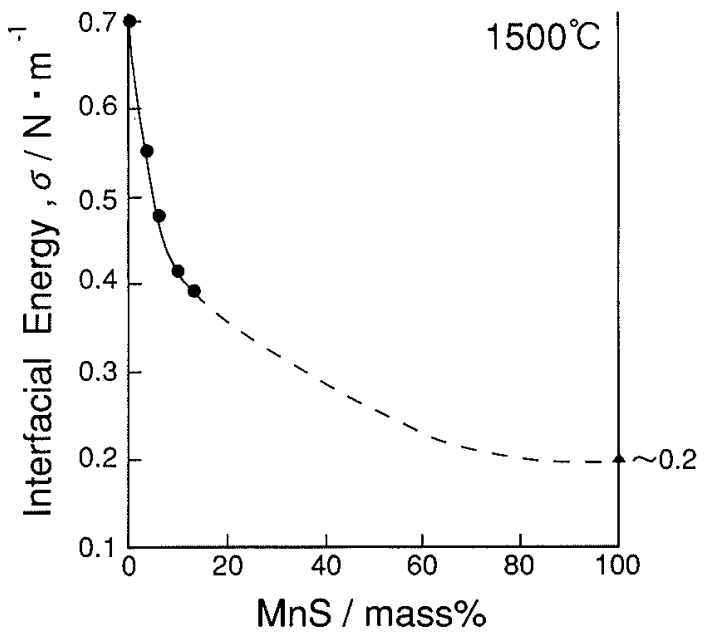

Fig. 11. Estimation of interfacial energy between $\mathrm{Fe}\left(\mathrm{L}_{1}\right)$ and $\mathrm{MnS}\left(\mathrm{L}_{2}\right)$ from the data on interface between $\mathrm{Fe}\left(\mathrm{L}_{1}\right)$ and slag $\left(\mathrm{MnO}-\mathrm{SiO}_{2}-\mathrm{CaO}-\mathrm{MnS}\right) .{ }^{14)}$

Table 2. Estimation of interfacial energy between liquid $\mathrm{Fe}$ and $\mathrm{MnS}$ from the data on various interfaces.

\begin{tabular}{|c|c|c|}
\hline Interface & Energy $/ \mathrm{N} \cdot \mathrm{m}^{-1}$ & Reference \\
\hline liq. Fe/liq. $\mathrm{MnS}$ & 0.2 (estimated) & 14) \\
\hline liq. $\mathrm{Fe} / \mathrm{liq} \mathrm{MnO}-\mathrm{SiO}_{2}-\mathrm{CaO}$ & 0.7 & 14) \\
\hline liq. $\mathrm{Cu}$ /liq. $\mathrm{Cu}_{2} \mathrm{~S}$ & 0.1 & 16) \\
\hline liq. $\mathrm{Fe} /$ sol. $\mathrm{MnS}$ & 0.6 (estimated) & \\
\hline liq. $\mathrm{Fe} / \mathrm{sol} . \mathrm{Al}_{2} \mathrm{O}_{3}$ & 1.8 & 18) \\
\hline liq. $\mathrm{Cu}_{2} \mathrm{~S} / \mathrm{sol} . \mathrm{Fe}$ & 0.47 & 16) \\
\hline liq. FeS/sol. Fe & 0.4 & 17) \\
\hline liq. $\mathrm{Fe} / \mathrm{sol} . \mathrm{Fe}$ & 0.2 & 15) \\
\hline sol. Fe/sol. MnS & 1.0 & 17) \\
\hline $\begin{array}{l}\text { sol. } \mathrm{Fe} / \mathrm{sol} . \mathrm{Fe} \\
\text { (random grain boundary) }\end{array}$ & 0.85 & 16) \\
\hline
\end{tabular}

11. This value seems reasonable when one compares it with the value of interfacial energy of $0.1 \mathrm{~N} / \mathrm{m}$ reported for the $\mathrm{Cu}(\mathrm{L}) / \mathrm{Cu}_{2} \mathrm{~S}(\mathrm{~L})^{16)}$ interface. As for the value of interfacial energy between $\mathrm{Fe}\left(\mathrm{L}_{1}\right)$ and $\mathrm{MnS}(\mathrm{s})$ it is estimated to be $0.6 \mathrm{~N} / \mathrm{m}$ by referring to the interfacial energies between $\mathrm{Fe}(\mathrm{s})$ and $\mathrm{MnS}(\mathrm{s}), \mathrm{FeS}(\mathrm{L})$ and $\mathrm{Cu}_{2} \mathrm{~S}(\mathrm{~L})$ listed in Table. 2.

It is immediately obvious from the above estimates of interfacial energies that $\mathrm{MnS}$ (s) nucleation would require three times large extent of the undercooling for a given critical radius (from Eq. (6)), and the energy barrier for its nucleation would also be three times larger (from Eq. (7)) when compared to the undercooling and energy barriers required for $\mathrm{MnS}\left(\mathrm{L}_{2}\right)$ nucleation for the same critical radius. It is therefore concluded that, during the solidification of the Fe-Mn-S ternary melt, the nucleation of $\mathrm{MnS}\left(\mathrm{L}_{2}\right)$ is energetically more favored than the nucleation of $\mathrm{MnS}(\mathrm{s})$, and the metastable monotectic reaction would predominate over the stable eutectic reaction.

\subsection{Effect of Additional Elements}

\subsubsection{Effect on Nucleation of MnS}

It has been mentioned in the preceding sections
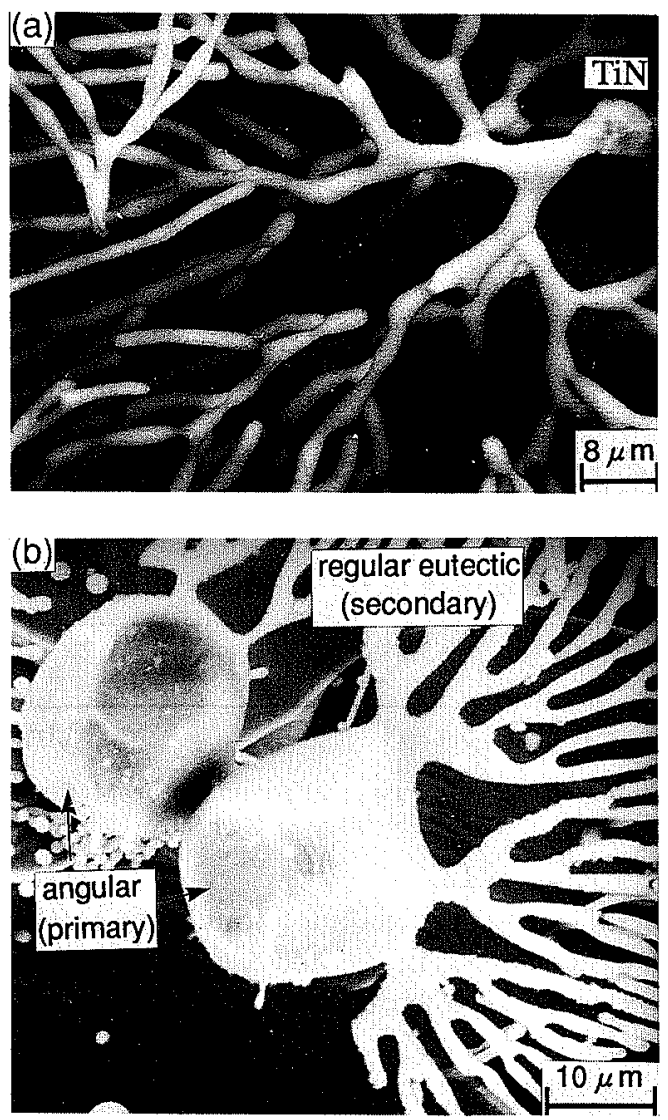

Fig. 12. Rod-like eutectic MnS developed from (a) cubic TiN in $\mathrm{Fe}-1 \% \mathrm{Mn}-0.3 \% \mathrm{~S}-0.1 \% \mathrm{Ti}$ and (b) primary angular $\mathrm{MnS}$ in $\mathrm{Fe}-2.5 \% \mathrm{Mn}-1.3 \% \mathrm{~S}-0.5 \% \mathrm{Al}-0.1 \% \mathrm{Ti}$ melted under $\mathrm{N}_{2}$.

elsewhere, that while the angular, dendritic and rodlike $\mathrm{MnS}$ were observed in the specimens containing $\mathrm{Al}$ (melted under $\mathrm{Ar}$ ) and $\mathrm{Ti}$ (melted under $\mathrm{N}_{2}$ ), only monotectic $\mathrm{MnS}$ was observed in the alloys containing Ti melted under Ar. The difference in the morphologies observed in the two cases of melting atmosphere are explained as follows: In the case of alloys containing $\mathrm{Ti}$ (melted under $\mathrm{N}_{2}$ ) and alloys containing $\mathrm{Al}$ (melted under $\mathrm{Ar}$ ), TiN and $\mathrm{Al}_{2} \mathrm{O}_{3}$ crystallities respectively, act as nucleation catalysts for $\mathrm{MnS}$ (s), promoting primary crystallization of the $\mathrm{MnS}(\mathrm{s})$ phase and the eutectic reaction of the stable system. Figure 12 shows the eutectic MnS developed from (a) a cubic TiN crystal and (b) an angular $\mathrm{MnS}$ which had also probably nucleated from TiN. The solid particles such as TiN and $\mathrm{Al}_{2} \mathrm{O}_{3}$ are more effective nucleants for $\mathrm{MnS}$ (s) than liquid particles because such solid particles with smaller solubilities and higher melting points are likely to be more favorable heterogeneous nucleating agents for $\mathrm{MnS}$ (s) phase. On comparing the melting points of oxides, nitrides and sulfides related to this study, it is seen that the compound with the highest melting point is TiN and the one next to it is $\mathrm{Al}_{2} \mathrm{O}_{3}$. It is therefore clear that in alloys melted under $\mathrm{N}_{2}$ atmosphere TiN has acted as the nucleant for the $\mathrm{MnS}$ (s) phase forcing the solidification path to follow the stable reaction. In the case of alloys melted under an $\mathrm{Ar}$ atmosphere only oxides $\mathrm{TiO}_{2}$ and $\mathrm{SiO}_{2}$ are formed and they combine with $\mathrm{MnO}$, forming compounds of lower melting temperature, although their 


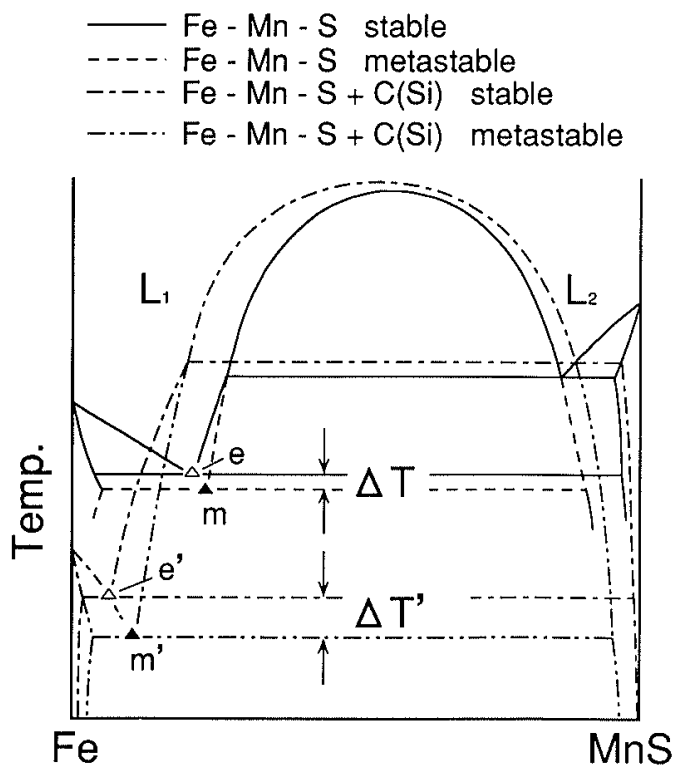

Fig. 13. Changes in phase equilibria in the $\mathrm{Fe}-\mathrm{MnS}$ pseudobinary system by alloying $\mathrm{C}$ or $\mathrm{Si}$.

own melting temperatures are about $100^{\circ} \mathrm{C}$ higher than $\mathrm{Fe}^{19,20)}$ As a result, in the alloys containing Ti melted under Ar, liquid oxide droplets are formed first, acting as nucleants for $\mathrm{MnS}\left(\mathrm{L}_{2}\right)$, thereby favoring the metastable monotectic reaction leading to the monotectic morphology of $\mathrm{MnS}$ in these alloys.

\subsubsection{Effect of $\mathrm{C}$ and $\mathrm{Si}$}

Figures 4 and 8 show the eutectic, dendritic, angular and irregular eutectic $\mathrm{MnS}$ observed in the specimens containing $\mathrm{C}$ or Si. The reason for these morphologies has sometimes been ascribed to the deoxidization of melt by these elements. ${ }^{3-8)}$ However, it has been pointed out earlier that the MnS morphology is not so sensitive to the oxygen content, so the reason must lie elsewhere. An explanation is given here based on the fact that $\mathrm{C}$ and Si lower the melting point of iron and raise the activity of sulfur. This would result in the expansion of the 2-liquid region and increase in the slope of the liquidus line for iron, leading to an increase in the temperature difference between the metastable monotectic and stable eutectic points as shown in Fig. 13. From a thermodynamic analysis, this difference in temperature is estimated to be about $10^{\circ} \mathrm{C}$ in the $\mathrm{Fe}-1 \% \mathrm{Mn}-0.3 \% \mathrm{~S}-$ $1 \% \mathrm{C}$ alloy. This could explain why the stable eutectic reaction develops more easily in preference to the metastable monotectic reaction. When large amounts of $\mathrm{C}$ and $\mathrm{Si}$ are added, the eutectic point is moved closer to the iron side of the phase diagram. In such a case, it is known that a divorced eutectic reaction can often occur. This may be the reason for the formation of irregular eutectic $\mathrm{MnS}$ at higher concentrations of $\mathrm{C}$ and $\mathrm{Si}$ in these systems.

\section{Conclusions}

The morphology of $\mathrm{MnS}$ found in cast $\mathrm{Fe}-\mathrm{Mn}-\mathrm{S}$ steels is classified and their occurrence explained on the basis of stable and metastable phase diagrams.

(1) The morphology of $\mathrm{MnS}$ formed by primary crystallization in sulfur-rich alloys is classified under a first set of three types as; (i) spherical, (ii) dendritic, and (iii) angular, while the morphology of the secondary $\mathrm{MnS}$ formed in sulfur-lean alloys is classified under a different set of three types as; (i) monotectic, (ii) eutectic, (iii) irregular eutectic.

(2) The monotectic and spherical types of $\mathrm{MnS}$ are formed through metastable reactions, while the other types of $\mathrm{MnS}$ are formed by stable reactions.

(3) Solid particles like TiN and $\mathrm{Al}_{2} \mathrm{O}_{3}$ promote the stable eutectic reaction, dendritic and the angular morphology by acting as nucleants for the MnS crystalline phase. Molten oxide droplets such as the oxide of $\mathrm{Ti}-\mathrm{Mn}-\mathrm{O}$ system act as nucleants for the separation of liquid $\mathrm{MnS}$ and promote the metastable reaction leading to monotectic $\mathrm{MnS}$ morphology.

(4) $\mathrm{C}$ and $\mathrm{Si}$ raise the activity of sulfur in iron and lower the melting point of iron, enlarging the temperature difference between the eutectic and monotectic points, and thereby promoting the stable eutectic reaction.

\section{Acknowledgment}

The authors would like to thank Mr. Yoshio Kawashita for his help in carrying out this study.

\section{REFERENCES}

1) J. Takamura and S. Mizoguti: Proc. of 6th Int. Iron and Steel Cong., Vol. I, ISIJ, Tokyo (1990), 591.

2) C. E. Sims and F. B. Dahle: Trans. Am. Foundarymen's Ass., 46 (1938), 65.

3) W. Dahl, H. Hengstenberg and G. Düren: Stahl Eisen, 86 (1966), 782.

4) P. P. Mohla and J. Beech: J. Iron Steel Inst., 207 (1969), 177.

5) H. Fredriksson and M. Hillert: J. Iron Steel Inst., 209 (1971), 109.

6) H. Fredriksson and M. Hillert: Scand. J. Metall, 2 (1973), 125.

7) T. J. Baker and J. A. Charles: J. Iron Steel Inst., 210 (1972), 702.

8) L. K. Bigelow and M. G. Flemings: Metall. Trans., 6B (1975), 275.

9) J. H. Andrew, W. R. Maddocks and E. A. Fowler; J. Iron Steel Inst., 124 (1931), 295.

10) R. Vogel and W. Hotop: Arch. Eisenhüttenwes., 11 (1937), 41.

11) N. Sano, M. Iwata, H. Hosoda and Y. Matsushita: Tetsu-toHagané, 57 (1971), 1984.

12) M. Hillert and L-I Staffansson: Metall. Trans., 7B (1976), 203.

13) H. Ohtani and T. Nishizawa: Trans Iron Steel Inst. Jpn., 26 (1986), 655.

14) Sh. M. Mikrashivili and A. M. Samarin: "Fiziko-Khimicheskie Osnovy Proizvodstua Stali", Nauk., (1964), 42.

15) D. Turnbull: J. Chem. Phys., 18 (1950), 769.

16) L. H. Van Vlack: Trans. AIME, 191 (1951), 251.

17) L. H. Van Vlack, O. K. Riegger, R. J. Warrick and J. M. Dahl: Trans. Metall. Soc. AIME, 221 (1961), 220.

18) K. Ogino, A. Adachi and K. Nogi: Tetsu-to-Hagane, 59 (1973), 1237.

19) J. White, D. D. Howatt and R.Hay: J. Roy. Tech. Coll. (Glasgow), 3 (1933-36), 239.

20) J. Greive and J. White: J. Roy. Tech. Coll. (Glasgow), 4 (1940), 661 .

(Originally published in Tetsu-to-Hagané, 80 (1994), 623, in Japanese) 